\title{
Poly I:C induces a protective antiviral immune response in the Pacific oyster (Crassostrea gigas) against subsequent challenge with Ostreid herpesvirus (OsHV-1 $\mu \mathrm{var}$ )
}

\author{
Timothy J. Green*, Caroline Montagnani
}

Ifremer, UMR 5119 "Ecology of Coastal Marine Systems", Université Montpellier 2, Place Eugène Bataillon, CC80, 30495 Montpellier Cedex 05, France

*: Corresponding author : Timothy J. Green, email address : Tim.Green@flinders.edu.au

\begin{abstract}
:
In-vivo studies were carried out to investigate the protective effect of a synthetic viral analogue (poly $\mathrm{I}: \mathrm{C})$ against Ostreid herpes virus (OsHV-1 $\mu \mathrm{var}$ ). Pacific oysters (Crassostrea gigas) were immuneprimed by intramuscular injection of $240 \mu \mathrm{g}$ of poly I:C or sterile seawater at 1 day prior to infection with OsHV-1 $\mu$ var. Poly I:C injection induced an antiviral state in C. gigas as the percentage of viralinfected oysters at $48 \mathrm{~h}$ post infection was significantly lower in the poly I:C treatment (11\%) compared to seawater controls $(100 \%)$. In an additional experiment, we demonstrated that the protective role of poly I:C is reproducible and elicits a specific antiviral response as immune-priming with heat-killed Vibrio splendidus provided no protection against subsequent viral infection. In both experiments, genes homologous to a toll-like receptor (TLR), MyD88, interferon regulatory factor (IRF) and protein kinase $\mathrm{R}(\mathrm{PKR})$ were up-regulated in oysters immune-primed with poly I:C compared to seawater controls $(p<0.05)$. The MyD88, IRF and PKR genes were also significantly up-regulated in response to OsHV-1 $\mu$ var infection $(p<0.05)$, which is suggestive that they are implicated in the antiviral response of $C$. gigas. Our results demonstrate that $C$. gigas can recognise double-strand RNA to initiate an innate immune response that inhibits viral infection. The observed response has striking similarities to the hallmarks of the type-1 interferon response of vertebrates.
\end{abstract}

\section{Highlights}

Poly I:C injection induced Crassostrea gigas into an antiviral state $>$ Poly I:C injection upregulated a TLR, Rel/NF-KB, IRF and PKR P Poly I:C injection reduced the proportion of oyster positive to OsHV-1 challenge Injection of heat-killed Vibrio provided no protection against subsequent OsHV-1 challenge.

Keywords: Crassostrea gigas ; OsHV-1 ; Poly I:C ; Vibrio splendidus; Interferon-like response 


\section{Introduction}

Innate immunity, the ancient immune system present in both invertebrates and vertebrates, is the first line of defence against microbial invaders, such as viruses. In vertebrates, the interferon signalling pathway is crucial for innate immunity against viral infection [1]. Most viruses produce double-stranded RNA (dsRNA) during viral replication and vertebrate cells recognise dsRNA (viral or synthetic) via toll-like receptor 3 , which triggers a complex signal-transduction pathway resulting in the translocation of transcription factors (NF-KB and interferon regulatory factor) to the cell nucleus and the up-regulation of a number of genes, principally interferon. Interferon exerts an antiviral state in neighbouring cells by inducing the expression of antiviral proteins, such as protein kinase $R$ (PKR), 2',5'-oligoadenylate synthetase (OAS), and Myxovirus resistance protein (Mx) [1]. Until recently, it was a generally accepted paradigm that the interferon-signalling pathway was absent from invertebrates, as genes homologous to interferon or its major effectors were absent in several fully sequenced invertebrate genomes [2]. Instead, it was believed invertebrates blocked viral replication by RNA interference (RNAi) and this mechanism of antiviral immunity is considered the primary and most important antiviral response in insects and crusteaceans, but has a lesser role in vertebrate innate immunity [3].

The Pacific oyster (Crassostrea gigas) is an economically valuable species farmed worldwide. Historically, Ostreid herpesvirus 1 (OsHV-1) has regularly been detected in C. gigas from France, United States and New Zealand [4-6]. OsHV-1 has typically only caused sporadic mortality events in larval and juvenile developmental stages of C. gigas [summarised by 5]. Since 2008, C. gigas have experienced increased mortality in France due to a new genotype of the Ostreid herpes virus, termed OsHV$1 \mu \operatorname{var}[7]$. Subsequently, the OsHV-1 $\mu$ var genotype has been confirmed to cause recurring mass mortalities in juvenile and adult developmental stages of $C$. gigas in Ireland, England, Spain, New Zealand and Australia [8]. The mortality caused by OsHV-1 $\mu$ var is influenced by environmental factors and the survival capacity of the host [9]. Oysters have no acquired immune system, but they do have efficient defence mechanisms for eliminating invading agents, based on an innate immune system. Over the last ten years, diverse feature of this defence system have been characterised in $C$. gigas, including signalling pathways, antimicrobial peptides and effectors [reviewed by 10]. However, knowledge of the antiviral immune response of molluscs is poorly understood and it would not be surprising if it differed from other model invertebrate species. This lack of knowledge has hampered the development of successful management solutions against this disease. Several genes induced by OsHV-1 infection have been reported in C. gigas [11], but thus far, no significant mechanistic insight into the molecular basis for antiviral immunity in $C$. gigas has been described.

We propose that an "interferon-like pathway" exists in molluscs (see Figure 1): Pearl oysters (Pinctada fucata) have receptors for interferon- $\Omega$ on the surface of their immuno-competent cells (hemocytes) [12] and injection of recombinant interferon- $\Omega$ prior to challenge with Akoya virus provides increased protection [13]. Furthermore, treatment of hemocytes with interferon- $\gamma$ was shown to activate a STAT-like pathway in the bivalve, Mytilus galloproviancialis [14]. Expressed sequence tags with high homology to interferon regulatory factors (IRFs) have been identified from flat oysters (Ostrea edulis), Pacific oysters (C. gigas) and mussels (M. edulis) [15-18], and the Mx gene, a classic interferon induced antiviral effector of vertebrates was reported in a gastropod (Haliotis discus discus) [19]. Complete genome sequences of primitive invertebrates indicate ancient origins for many components of the vertebrate innate 
immune system with significant gene loss likely having occurred in model invertebrate species [20, 21]. It appears that the OAS gene was lost from Ecdysozoa, as OAS activity was shown in crude extracts from the sponge, Geodia cydonium [22]. Furthermore, the OAS gene was recently isolated from the sponge, Lubomirskia baicalensis and its expression was significantly up-regulated following exposure to poly I:C, a known powerful inducer of type-1 interferon response in vertebrates [23].

Studies conducted in fish have demonstrated that poly I:C injection induces an interferon response [24] that can provide protection against subsequent viral infection $[25,26]$. Previously, it was demonstrated that poly I:C injection was a powerful inducer of putative antiviral gene expression in the Sydney rock oyster, Saccostrea glomerata [27]. Synergies in the pathways and genes expressed by S. glomerata following poly I:C injection were observed with $C$. gigas experimentally infected with OsHV-1 [11]. It is also known that injection of dsRNA (poly G:C) in marine shrimp (Litpenaeus vannamei) induces an innate immune response that provides increased protection against two unrelated viruses, white spot syndrome virus and Taura syndrome virus [2]. Therefore, we investigated whether poly I:C injection could induce $C$. gigas into an antiviral state that provided protection against subsequent OsHV-1 $\mu$ var infection. In parallel, we measured the expression of nine putative antiviral genes to gain insight into the immune response of $C$. gigas. These genes included a TLR and IRF identified in a cDNA library generated from short read sequences of $C$. gigas exposed to varying degrees of anthropogenic impacts [15] and homologues of PKR and OAS, which were identified in the recently completed oyster genome [18]. We also selected genes from the NF-kB pathway that have been identified in C. gigas: the NF-kB homolog $C g$-Rel and its inhibitor, $C g$-IkB [28, 29]. The remaining genes chosen for qRT-PCR analysis were shown to be upregulated in $C$. gigas in response to OsHV-1 infection [11].

\section{Materials and Methods}

\subsection{Experimental Animals Poly I:C protection studies}

Specific pathogen free Crassostrea gigas were produced on the $5^{\text {th }}$ of March, 2012, at the Ifremer oyster hatchery in La Tremblade, Charente Maritime, France. These oysters were confirmed to be free of OsHV-1 and its variants throughout the larval and spat production cycle. Oyster spat were on-grown in a biosecure nursery facility before being transferred to Ifremer's Aquaculture Research Facility in Palavas-lesFlots (Laboratoire Aquaculture en Languedoc -Roussillon, LALR), Southern France. These oyster spat (mean weight $=3.8$ grams) were used for experimentation in this manuscript, unless otherwise stated.

\subsection{Preparation of OsHV-1 $\mu$ var and control oyster homogenates}

An initial oyster homogenate was prepared according to Schikorski and Colleagues [30] from five moribund oyster spat collected during a mortality event on the $30^{\text {th }}$ of May, 2012 from Thau Lagoon, France. Briefly, gill and mantle tissue was excised, pooled and homogenised in 4-volumes of sterile seawater using an Ultraturax mixer. The oyster homogenate was clarified by centrifugation (1000 x g for $10 \mathrm{~min}$ ) before serial filtration $(8.0,0.45$ and $0.22 \mu \mathrm{m})$ in sterile conditions. OsHV-1 $\mu$ var was confirmed in this oyster homogenate by visualisation of herpes-like viral particles by electron microscopy (not pictured) and the genotype confirmed by amplifying and sequencing the $\mathrm{C} 2 / \mathrm{C} 6$ region [7]. 
Eight healthy oyster spat (see above) were injected with $50 \mu \mathrm{l}$ of OsHV-1 $\mu$ var homogenate in the adductor muscle through a notch filed in the oyster shell. Oyster spat were then placed in $30 \mathrm{~L}$ aerated aquaria maintained at $22 \pm 2{ }^{\circ} \mathrm{C}$ without food supply for $48 \mathrm{hrs}$. The gill and mantle tissue was excised from these infected oyster spat and used to prepare a second OsHV-1 $\mu$ var homogenate as above. This second OsHV-1 $\mu$ var homogenate was used in the first poly I:C protection experiment and to prepare a third OsHV-1 $\mu$ var homogenate used in the second poly I:C protection experiment (see below).

Control oyster homogenates were also prepared as above from healthy oyster spat. OsHV-1 $\mu$ var and control oyster homogenates were confirmed to be either positive or below detectable limits ( $>45$ cycles of $\mathrm{qPCR}$ ) for the virus using the $\mathrm{C} 9 / \mathrm{C} 10$ primer pair (Table 1) and quantitative PCR parameters described by Pepin and Renault [31]. Since conventional cell culture methods for virus quantification is not possible for OsHV-1 $\mu$ var, a molecular method was employed to estimate the viral load in oyster homogenates and samples. The $\mathrm{C} 9 / \mathrm{C} 10$ amplification product was cloned into the pCR4-Topo vector and replicated in Escherichia coli DH5a (Invitrogen) according to the manufacturers protocol. The plasmid was extracted using a Wizard® Plus SV miniprep DNA purification system (Promega) and the concentration of plasmid determined by UV spectrophometry and calculations outlined in the Applied Biosystems manual of absolute real-time RT-PCR quantification [32]. A standard curve (PCR efficiency $\left.=95.0 \%, R^{2}=0.995\right)$ was generated by diluting the plasmid in distilled water and the viral load of samples was estimated by QPCR and comparing the observed Ct values to known plasmid standards. All oyster homogenates used for virus and control inoculations were stored at $4{ }^{\circ} \mathrm{C}$ for no longer than two weeks and confirmed to be free of culturable bacteria by plating $50 \mu \mathrm{l}$ of homogenate on marine agar (Difco, cat \#212185).

\subsection{Poly I:C protection studies}

Two in-vivo experiments were performed to determine the protective role of poly I:C. Prior to experimentation, each oyster had a notch carefully filed in the side of its shell adjacent to its adductor muscle using an electric bench grinder. The oysters were then acclimatised to their research aquaria for 72 hours prior to experimentation. Research aquaria were aerated and maintained at $22 \pm 2^{\circ} \mathrm{C}$ with an aquarium heater. In the first experiment, oysters were immune-primed at time $0 \mathrm{hr}$ with poly $\mathrm{I:C}(5$ mg. $\mathrm{ml}^{-1}$ in sterile seawater, Sigma, cat \#P9582). Two aquaria (A and B) with 15 oysters were injected with $50 \mu \mathrm{l}$ of poly I:C and another two aquaria (C and $D)$ of 15 oysters were injected with $50 \mu \mathrm{l}$ of sterile seawater (control treatment) into the adductor muscle using a 26-gauge needle attached to a multi-dispensing hand pipette. At 24 hours, remaining oysters in each aquarium were injected a second time with either $50 \mu \mathrm{l}$ of OsHV-1 $\mu$ var homogenate $\left(6.5 \times 10^{8}\right.$ copies of $\mathrm{C} 9 / \mathrm{C} 10 . \mu \mathrm{l}^{-1}$; aquaria $A$ and $C$ ) or with the control homogenate (B and $D)$. Preparation of oyster homogenates is described above. Three oysters from each aquarium were sampled at the 0 and $24 \mathrm{hr}$ time points and the remaining nine oysters in each aquarium were sampled at 72 hours. Sampling consisted of individually shucking each oyster with a sterile scapbel blade and the whole oyster was snap-frozen in liquid nitrogen in individual plastic bags. The oysters were stored at $-80^{\circ} \mathrm{C}$ until nucleic acid purification.

A second experiment was conducted as above, except at time $0 \mathrm{hrs}$, oyster spat were primed with either $50 \mu \mathrm{l}$ of poly I:C (aquaria $A, B, C$ and $D$ ), heat inactivated $V$. splendidus LGP32 (aquaria E, F, G and H) or sterile seawater (aquaria I, J, K and L). $V$. splendidus was prepared by culturing the bacterium in marine broth 2216 (Difco, 
cat \#279110) overnight at $20^{\circ} \mathrm{C}$ with shaking. $\quad V$. splendidus were then pelleted by centrifugation (1000 x g, $10 \mathrm{~min}$ ), washed and resuspended in sterile seawater to an OD600 $=0.505$ (equivalent to $10^{8} \mathrm{CFU} \cdot \mathrm{ml}^{-1}$ ) before heat-inactivation at $95^{\circ} \mathrm{C}$ for 15 min. At 24 hours, oysters were injected with either $50 \mu \mathrm{l}$ of OsHV-1 $\mu$ var homogenate $\left(2.1 \times 10^{8}\right.$ copies of $C 9 / C 10 . \mu I^{-1}$; aquaria $A, B, E, F, I$ and $\left.J\right)$ or with the control homogenate (aquaria C, D, G, H, K and L). Three oysters from each aquarium were sampled at the 0 and $24 \mathrm{hr}$ time points and four oysters from each aquarium were sampled at 72 hours as above.

\subsection{Nucleic Acid Purification and Reverse Transcription}

Individual whole oysters were ground to a homogenised powder by beat-beating (Retsch, MM 400) samples with a stainless steel ball bearing and housing that had been pre-chilled in liquid nitrogen. Genomic DNA was purified from homogenised oyster tissue using UltraPure ${ }^{T M}$ Phenol: Chloroform: Isoamyl Alcohol (Invitrogen, Cat \#15593-049) before being pelleted with isopropanol and washed with $70 \%$ ethanol. Total RNA was purified using TRIzol ${ }^{\circledR}$ Reagent (Invitrogen, Cat \#15596-018) and DNA contamination eliminated with recombinant DNase I (Ambion, Cat \#AM2222). The purity and quantity of purified nucleic acids was estimated by spectrophometry (Thermo Scientific, ND-1000) and quality assessed by agarose gel electrophoresis. Genomic DNA and total RNA were resuspended in sterile water to a final concentration of 20 and $100 \mathrm{ng} / \mu \mathrm{l}$, respectively. First-strand synthesis was performed on $500 \mathrm{ng}$ of total RNA using $250 \mathrm{ng}$ of random hexamer primers (Invitrogen, cat \#48190-011) and 200 units of M-MLV reverse transcriptase (Invitrogen, cat \#28025-013). cDNA was diluted ten-fold in sterile water prior to use.

\subsection{OsHV-1 DNA quantification}

The detection and quantification of OsHV-1 DNA was performed according to Pepin and Renault [31] using a LightCycler $₫ 480$ Real-Time thermocycler (Roche). PCR reaction volumes were $6 \mu$ containing LightCycler ${ }^{\circledR} 480$ SYBR Green I Master mix (Roche), $100 \mathrm{nM}$ of $\mathrm{C} 9$ forward and C10 reverse primers (Table 1) and $20 \mathrm{ng}$ of DNA. All PCR reactions were performed in duplicate and absolute quantification of OsHV-1 DNA copies was estimated as described above. Chi-square analysis was used to compare the frequency that OsHV-1 DNA was detected by qPCR in each experimental treatment.

\subsection{Gene Expression Analysis}

Nine putative antiviral genes were selected for qRT-PCR analysis using the gene specific primers listed in Table 1. The PCR reaction volume was $6 \mu$ land contained LightCycler $\circledR 480$ SYBR Green I Master mix (Roche), $100 \mathrm{nM}$ of each specific primer and $2.5 \mathrm{ng}$ of cDNA in a LightCycler ${ }^{\circledR} 480$ Real-Time thermocycler (Roche) using an initial denaturation $\left(95^{\circ} \mathrm{C}\right.$ for $\left.5 \mathrm{~min}\right)$ followed by 45 cycles of denaturation $\left(95^{\circ} \mathrm{C}, 10\right.$ $\mathrm{sec})$, hybridisation $\left(60^{\circ} \mathrm{C}, 20 \mathrm{sec}\right)$ and elongation steps $\left(72^{\circ} \mathrm{C}, 25 \mathrm{sec}\right) . \mathrm{A}$ subsequent melting temperature curve of the amplicon was performed. Amplification efficiency of target and reference genes was calculated using a 5-fold dilution of cDNA and the amplification efficiency for each primer pair is listed in Table 1. Expression of target genes were normalised with the elongation factor 1-alpha reference gene [33], which was stable in the current study. The relative expression of target genes was firstly calculated using the $\Delta \mathrm{Ct}$ method using the formula: $2^{\mathrm{Ct}(\text { target)-Ct(reference) }}$, with the cycle threshold $(\mathrm{Ct})$ set at 0.1 for all genes. The normalised expression ratio $\left(2^{-\Delta \Delta C t}\right)$ was calculated using the relative expression of 
target genes at time $0 \mathrm{hr}$ as the calibrator according to Livak and Schmittgen [34]. Two-way analysis of variance (ANOVA) was performed to test the effect of immunepriming and OsHV-1 $\mu$ var infection on the normalised expression of each target gene using the computer software package, GraphPad Prism® v. 6.0a. Tukey's honest significant difference method for multiple comparisons was used to compare means if significant differences were found.

\section{Results}

\subsection{Poly I:C provides protection against subsequent OsHV-1 $\mu$ var infection}

Two independent experiments were performed to examine whether poly $\mathrm{I}: \mathrm{C}$ treatment could confer protection against OsHV-1 $\mu$ var infection. In the first experiment, poly I:C injection provided oysters with significant protection against OsHV-1 $\mu$ var infection (Figure $1 \mathrm{~A}, X^{2}=31.57$, df $=3, p<0.0001$ ). In the poly I:C group, only one of the nine individual oysters $(11 \%)$ contained OsHV-1 $\mu$ var DNA at 48 hours post infection. In contrast, the proportion of oysters containing OsHV-1 $\mu$ var DNA was nine for nine individual oysters $(100 \%)$ in the control group (Figure 2A). A second experiment was performed in order to confirm this initial result and to determine if the protection was specific to poly I:C. This initial result was confirmed and shown to be a specific antiviral response (Figure 1B, $X^{2}=38.62$, df $=5, p<$ $0.0001)$. In the poly I:C group, two of eight individual oysters $(25 \%)$ contained OsHV-1 4 var DNA compared to eight of eight individual oysters $(100 \%)$ in the control group (Figure 2B). Furthermore, the protection provided by poly I:C appears to be specific as no protection was observed from oysters injected with heat-killed $V$. splendidus. In the V. splendidus group, eight of eight individual oysters (100\%) contained OsHV-1 $\mu$ var DNA and their estimated viral load was significantly higher compared to oysters injected with poly $\mathrm{I}: \mathrm{C}$ prior to virus challenge (Figure 2B, ANOVA, $p<0.01$ ).

\subsection{Gene Expression}

The experimental design employed in the current study allowed us to determine if immune-priming or OsHV-1 $\mu$ var infection up-regulated the expression of nine putative antiviral genes. Poly I:C priming was observed to up-regulate the expression of $\mathrm{Cg}$-TLR in both experiments (Figure $3 \mathrm{~A}$ and $3 \mathrm{~B}, p<0.05$ ), but was not significantly upregulated following OsHV-1 infection $(p>0.05)$. The expression of Cg-MyD88 was significantly up-regulated in response to poly I:C priming in experiment 1 (Figure 3C, $p<0.01$ ) and OsHV-1 $\mu$ var infection in experiment 2 (Figure 3D, $p<0.0001$ ). The expression levels of $\mathrm{Cg}$-Rel and $\mathrm{Cg}$-IRF were only measured in protection experiment two and both of these genes were found to be significantly up-regulated in response to poly $\mathrm{I}: \mathrm{C}$ injection (Figure $3 \mathrm{E}$ and $3 \mathrm{~F}, p<$ 0.0001 ) and $\mathrm{Cg}$-IRF was also significantly up-regulated in response to OsHV-1 $\mu$ var infection (Figure 3F, $p<0.0001$ ). In both experiments, the expression of Cg-Mpeg1 was up-regulated in response to poly I:C priming (Figure $3 \mathrm{G}$ and $3 \mathrm{H}, p<0.001$ ) and OsHV-1 $\mu$ var infection (Figure $3 \mathrm{G}$ and $3 \mathrm{H}, p<0.01$ ). The expression of $\mathrm{Cg}-\mathrm{PKR}$ was significantly up-regulated in response to OsHV-1 $\mu$ var in experiment 1 (Figure 3I, $p<$ 0.01 ) and poly I:C priming in experiment 2 (Figure $3 \mathrm{~J}, p<0.0001$ ). The expression of Cg-IFI44 was significantly up-regulated in response to poly I:C injection (Figure $2 \mathrm{~K}, p<0.01$ ) and OsHV-1 $\mu$ var infection (Figure $3 \mathrm{~K}, p<0.05$ ) in the first experiment. However, the expression of expression of Cg-IFI44 was stable in the second experiment (Figure 3L, $p>0.05$ ). Finally, immune priming or OsHV-1 $\mu$ var infection had no significant effect on the expression of Cg-IkB or Cg-OAS $(p>0.05)$. 


\section{Discussion}

We have shown that poly I:C acts to stimulate an antiviral state in $C$. gigas that interferes with OsHV-1 $\mu$ var infection. The proportion of oysters positive for OsHV-1 was markedly reduced in oysters treated with poly I:C (Figure 2). Furthermore, poly $\mathrm{I}: \mathrm{C}$ induced a specific antiviral response as opposed to a generic immune response because priming oysters with heat-inactivated $V$. splendidus bacteria did not reduce the proportion of oysters infected by OsHV-1 $\mu$ var (Figure 2B). Similar protective responses have been observed in vertebrates and marine shrimp. Numerous studies in fish have demonstrated that poly I:C induces the expression of interferon stimulated genes and inhibits viral replication in cell lines and in vivo [25, 26, 35, 36]. Poly I:C injection in channel catfish (Ictalurus punctatus) prior to challenge with a herpesvirus (channel catfish virus or CCV) resulted in the upregulation of Myxovirus resistance $(\mathrm{Mx}) \mathrm{mRNA}$ and significantly reduced mortality from $70 \%$ to $3 \%$ [26]. Studies conducted in channel catfish ovary (CCO) cell lines have demonstrated that poly I:C treatment induces the expression of catfish interferon-2 and $\mathrm{Mx}[37,38]$ and this response effectively blocks channel catfish virus replication in CCO cells by inhibiting immediate-early gene expression of the virus [36].

We measured the expression of nine putative antiviral genes in the current study to provide insight into the molecular mechanism that conferred resistance against OsHV-1 $\mu$ var infection. It is not currently possible to propagate OsHV-1 in a mollusc cell line and prepare pure viral inoculums. Protocols developed for OsHV-1 experimental infections rely on preparing infectious tissue homogenates from infected oyster tissues [11,30]. These crude oyster homogenates would contain microbial products and host cellular debris that may induce immune and tissue damage response pathways. We therefore included a control oyster homogenate to determine if our target genes were induced by OsHV-1 $\mu$ var infection or by the oyster homogenate. Comparison of putative antiviral gene expression between the two protective studies revealed Cg-TLR, Cg-IKB, Cg-Mpeg1 and Cg-OAS had similar expression patterns between the two protective studies. However, the expression profiles of $\mathrm{Cg}-\mathrm{MyD} 88, \mathrm{Cg}-\mathrm{PKR}$ and $\mathrm{Cg}-\mathrm{IFI} 44$ were different and probably reflect methodology constraints, including small sample sizes and the inability to quantify and standardise the number of infectious virus particles in OsHV-1 $\mu$ var homogenates leading to differences in infection kinetics between the two studies. Previous research has demonstrated that varying the infectious dose (dilution) of AVNV (herpesvirus) alters the infection kinetics and survival of the scallop, Chlamys farreri [39]. Renault and Colleagues [11] have already demonstrated that the expression level of Cg-MyD88, Cg-Mpeg1 and Cg-IFI44 is positively correlated with OsHV-1 load. Reassuringly, both poly I:C injection and OsHV-1 $\mu$ var infection increased the mean expression of Cg-MyD88 and Cg-PKR in both experiments (Figure 3). The conflicting result for $\mathrm{Cg}$-IFI44 between the two protective experiments is likely the result that Cg-IFI44 mRNA levels were either absent or below detectable limits for a large number of individual oyster in the second experiment, which ultimately would reduce the power to determine statistical differences. Rosa and Colleagues [40] have previously reported the inability to detect Cg-IFI44 mRNA by qRT-PCR in a large percentage of individual oysters and they speculated either single nucleotide polymorphisms prevented particular $\mathrm{Cg}$ IFI44 alleles to be amplified or absence of the IFI44 gene in the genome of a proportion of the $C$. gigas population.

Vertebrates cells recognise poly I:C using toll-like receptor 3, which triggers activation of the transcription factors IRF-3 and NF-KB that translocate into the nucleus and attach to specific sites in the interferon gene promoter [24]. Similar to 
vertebrates, we observed in $C$. gigas that poly I:C injection up-regulated the response of a toll-like receptor, an interferon regulatory factor and Rel/NF-kB (Figure 3). Poly $\mathrm{I}: \mathrm{C}$ injection also up-regulated the expression of $\mathrm{Cg}$-IFI44 in protective experiment 1 and $\mathrm{Cg}-\mathrm{PKR}$ in protective experiment 2. Both of these genes are homologues of vertebrate interferon stimulated genes (ISGs). The role of IFI44 in vertebrate antiviral immune response is unclear, but this gene is known to be up-regulated in oysters responding to viral infection [11,41]. In contrast, PKR is one of the most studied mammalian interferon-induced proteins and inhibits viral and cellular protein synthesis by phosphorylating eukaryotic initiation factor 2 (elF2) [24]. Poly I:C injection also upregulated the expression of $\mathrm{Cg}-\mathrm{Mpeg} 1$, which is a macrophage expressed gene (perforin) that plays an essential role in innate immunity. Cg-Mpeg1 is found predominantly in the late endosomes and exhibits significant antibacterial activity [42] and Renault and Colleagues [11] speculated it may be involved in direct killing of viral infected host cells and/or inactivating OsHV-1 through virus envelope degradation.

The genes up-regulated to poly I:C injection were likely to be also involved in the antiviral response of $C$. gigas. Renault and Colleagues [11] previously demonstrated that MyD88, Mpeg1 and IFI44 are up-regulated in C. gigas experimentally infected with OsHV-1, but this is the first report that the expression Cg-IRF and Cg-PKR is induced by OsHV-1 infection and Cg-TLR and Cg-Rel is regulated in response to dsRNA. It was recently reported that Cg-TLR 3 (Genbank \# AM854726), NF-kB inhibitor cactus (Genbank \# AM853504) and suppressor of cytokine signalling (Genbank \# CU686145) were differentially expressed in gill, muscle and gonad tissues of $C$. gigas family lines bred for resistance or susceptibility to French summer mortality and subjected to a mortality outbreak in the field [43]. The authors concluded that the ability of resistant oysters to up-regulate the expression of these immune signaling genes just prior to the mortality peak was the main determinant for the difference in survival in the field [43]. Our results are in accordance with these observations. The expressed sequence tag for the TLR we studied has highest sequence homology to Cg-TLR 3 (BlastX 85 \% identity, Genbank EKC35956) and the TLR pathway is one of the most highly conserved signaling pathways for activation of NF-KB. The up-regulation of myeloid differentiation primary response protein 88 (MyD88) provides further support for involvement of the TLR/NF-KB signalling pathway in OsHV-1 resistance (Figure 3). We were surprised that OAS, a classic interferon simulated gene of vertebrates, was not upregulated in $C$. gigas following poly I:C injection or OsHV-1 $\mu$ var challenge. This observation is in contrast to studies conducted on vertebrates [1] and sponges [23], but we only measured the expression of one of the two OAS isoforms reported in the oyster genome [18].

In summary, we demonstrated oysters have an inducible antiviral immune response that is separate from a dsRNA gene silencing mechanisms (RNAi) by using a nonspecific dsRNA stimulant. Furthermore, this was a specific antiviral response as no protection was observed when oysters were injected with Vibrio splendidus prior to challenge. The observed response required the oysters to be able to recognise dsRNA to activate signalling cascades and up-regulate the expression of effector molecules that either blocked viral entry into host cells or inhibits viral replication. In support of this statement we observed increased mRNA levels for a toll-like receptor, transcription factors and antiviral effector proteins. Our observations in the current study had striking resemblance to a type-1 interferon response of vertebrates. Future research is now needed to firstly find out if oysters utilise other antiviral pathways, including RNAi, to combat viral infection and to secondly determine why adults, but not juveniles, can mount an effective immune response against OsHV-1 $\mu v a r$ infection. 


\section{Acknowledgements}

The authors would like to acknowledge the generosity of Steven Roberts (University of Washington) for sharing sequence data on the transcriptome of $C$. gigas. The authors are grateful to the Ifremer LGP, and the Bouin rearing facilities for quality oyster spat supply. We also thank the LALR (Palavas-les-Flots) and LER-LR (Sète) Ifremer laboratories for technical assistance during oyster trials and naturally infected oyster supply. The authors also acknowledge the laboratory assistance of Agnès Vergnes and Marc Leroy and the constructive editorial comments from an anonymous reviewer.

\section{References}

1. Randall RE, Goodbourn S. Interferons and viruses: an interplay between induction, signalling, antiviral responses and viral countermeasures. J Gen Virol. 2008 89:1-47.

2. Robalino J, Browdy CL, Prior S, Metz A, Parnell P, Gross PS, et al. Induction of antiviral immunity by double-stranded RNA in a marine invertebrate. Journal of Virology. 2004 78:10442-8.

3. Blair CD. Mosquito RNAi is the major innate immune pathway controlling arbovirus infection and transmission. Future Microbiol. 2011 6:265-77.

4. Friedman CS, Estes RM, Stokes NA, Burge CA, Hargove JS, Barber BJ, et al. Herpes virus in juvenile Pacific oysters Crassostrea gigas from Tomales Bay, California, coincides with summer mortality episodes. Dis Aquat Org. 2005 63:33-41.

5. Garcia D, Thebault A, Degremont L, Arzul I, Miossec L, Robert M, et al. Ostreid herpesvirus 1 detection and relationship with Crassostrea gigas spat mortality in France between 1998 and 2006. Vet Res. 2011 42:73-84.

6. Webb SC, Fidler A, Renault T. Primers for PCR-based detection of ostrid herpes virus-1 (OsHV-1): Application in a survey of New Zealand molluscs. Aquaculture. 2007 272:126-39.

7. Segarra A, Pepin JF, Arzul I, Morga B, Faury N, Renault T. Detection and description of a particular Ostreid herpesvirus 1 genotype associated with massive mortality outbreaks of Pacific oysters, Crassostrea gigas, in France in 2008. Virus Res. 2010 153:92-9.

8. Renault T, Moreau P, Faury N, Pepin J-F, Segarra A, Webb S. Analysis of clinical ostreid herpesvirus 1 (Malacoherpesviridae) specimens by sequencing amplified frangments from three virus genome areas. Journal of Virology. 2012 86:5942-7.

9. Peeler EJ, Allan Reese R, Cheslett D, Geoghegan F, Power A, Thrush MA. Investigation of mortality in Pacific oysters associated with Ostreid herpevirus-1 uvar in the Republic of Ireland in 20089. Prev Vet Med. 2012 105:136-43.

10. Schmitt P, Duperthuy M, Montagnani C, Bachere E, Destoumieux-Garzon D. Immune responses in the Pacific oyster Crassostrea gigas: an overview with focus on summer mortalities. In: Qin JG, editor. Oysters: physiology, ecological distribution and mortality: Nova Science Publishers; 2011, p. 311.

11. Renault T, Faury N, Barbosa-Solomieu V, Moreau K. Suppression substractive hybridisation (SSH) and real time PCR reveal differential gene expression in the Pacific cupped oyster, Crassostrea gigas, challenged with Ostreid herpesvirus 1. Dev Comp Immunol. 2011 35:725-35.

12. Miyazaki T, Taniguchi T, Hirayama J, Nozawa N. Receptors for recombinant feline interferon- omega in hemocytes of the Japanese pearl oyster Pinctada fucata martensii. Dis Aquat Org. 2002 51:135-8. 
13. Miyazaki T, Nozawa N, Kobayashi T. Clinical trial results on the use of a recombinant feline interferon- omega to protect Japanese pearl oysters Pinctada fucata martensii from akoya-virus infection. Dis Aquat Org. 2000 43:15-26.

14. Canesi L, Betti M, Ciacci C, Citterio B, Pruzzo C, Gallo G. Tyrosine kinasemediated cell signalling in the activation of Mytilus hemocytes: possible role of STATlike proteins. Biol Cell. 2003 95:603-13.

15. Gavery MR, Roberts SB. Characterizing short read sequencing for gene discovery and RNA-Seq analysis in Crassostrea gigas. Comp Biochem Physiol D. 2012 7:94-9.

16. Morga B, Arzul I, Faury N, Segarra A, Chollet B, Renault T. Molecular responses of Ostrea edulis haemocytes to an in vitro infection with Bonamia ostreae. Dev Comp Immunol. 2011 35:323-33.

17. Philipp EER, Kraemer L, Melzner F, Poustka AJ, Thieme S, Findeisen U, et al. Massively parallel RNA sequencing identifies a complex immune gene repertoire in the lophotrochozoan Mytilus edulis. Plos One. 2012 7:e33091.

18. Zhang G, Fang X, Guo X, al. e. The oyster genome reveals stress adaptation and complexity of shell formation. Nature. 2012 490:49-54.

19. de Zoysa M, Kang H-S, Song Y-B, Jee Y, Lee Y-D, Lee J. First report of invertebrate $\mathrm{Mx}$ : Cloning, characterization and expression anlysis of Mx cDNA in disk abalone (Haliotis disus discus). Fish Shellfish Immunol. 2007 23:86-96.

20. Hemmrich G, Miller DJ, Bosch TCG. The evolution of immunity: a low life perspective. Trends in Immunology. 2007 28:449-54.

21. Miller DJ, Hemmrich G, Ball EE, Haywar DC, Khalturin K, Funayama N, et al. The innate immune repertoire in Cnidaria - ancestral complexity and stohastic gene loss. Genome Biol. 20078.

22. Kuusksalu A, Subbi J, Pehk T, Reintamm T, Muller WEG, Kelve M. Identification of the reaction products of $\left(2^{\prime}-5^{\prime}\right)$ oligoadenylate synthetase in the marine sponge. Eur J Biochem. 1998 257:420-6.

23. Schr"oder HC, Natalio F, Wiens M, Tahir MN, Shukoor MI, Tremel W, et al. The 2'-5'-oligoadenylate synthetase in the lowest metazoa: isolation, cloning, expression and functional activity in the sponge Lubomirskia baicalensis. Mol Immunol. 2008 45:945-53.

24. Robertsen B. The interferon system of teleost fish. Fish Shellfish Immunol. 2006 20:172-91.

25. Fernandez-Trjuillo A, Ferro P, Garcia-Rosado E, Infante C, Alonso MC, Bejar $\mathrm{J}$, et al. Poly I:C induces Mx transcription and promotes an antiviral state against sole aquabirnavirus in the flatfish Senegalese sole (Solea senegalensis Kaup). Fish Shellfish Immunol. 2008 24:279-85.

26. Plant KP, Harbottle $\mathrm{H}$, Thune RL. Poly I:C induces an antiviral state agains Ictalurid Herpesvirus 1 and $M \times 1$ transcription in the channel catfish (Ictalurus punctatus). Dev Comp Immunol. 2005 29:627-35.

27. Green TJ, Barnes AC. Inhibitor of REL/NF-kB is regulated in Sydney rock oysters in response to specific double-stranded RNA and Vibrio alginolyticus, but the major immune anti-oxidants EcSOD and Prx6 are non-inducible. Fish Shellfish Immunol. 2009 27:260-5.

28. Montagnani C, Kappler C, Reichhart JM, Escoubas JM. Cg-Rel, the first Rel/NF-kB homolog characterized in a mollusk, the Pacific oyster Crassostrea gigas. FEBS Lett. 2004 561:75-82.

29. Montagnani C, Labreuche $\mathrm{Y}$, Escoubas JM. Cg-lkB, a new member of the IkB protein family characterised in the Pacific oyster Crassostrea gigas. Dev Comp Immunol. 2008 32:182-90.

30. Schikorski D, Renault T, Saulnier D, Faury N, Moreau P, Pepin JF. Experimental infection of Pacific oyster Crassostrea gigas spat by ostreid herpesvirus 1: demonstration of oyster spat susceptibility. Vet Res. 2011 42:27. 
31. Pepin JF, Renault T. Rapid and sensitive detection of ostreid herpesvirus 1 in oyster samples by real-time PCR. J Virol Methods. 2008 149:269-76.

32. Applied_Biosystems. Creating standard curves with genomic DNA or plasmid DNA templates for use in quantitative PCR. www.appliedbiosystems.com/support/tutorials/pdf/quant_pcr.pdf. 2003.

33. de Lorgeril J, Zenagui R, Rosa R, Piquemal D, Bachere E. Whole transcriptome profiling of successful immune response to Vibrio infections in the oyster Crassostrea gigas by digital gene expression analysis. Plos One. 2011 6:e23142.

34. Livak KJ, Schmittgen TD. Analysis of relative gene expression data using real-time quantitiative PCR and the 2-DDCT method. Methods. 2001 25:402-8.

35. Jensen I, Robertsen B. Effect of double-stranded RNA and interferon on the antiviral activity of Atlantic salmon cells against infectious salmon anemia virus and infectious pancreatic necrosis virus. Fish Shellfish Immunol. 2002 13:221-41.

36. Silverstein PS, Li R, Murdock C, Waldbieser GC. Poly I:C inhibits the expression of channel catfish virus immediate-early gene ORF 1 at early times after infection. Fish Shellfish Immunol. 2007 23:479-84.

37. Long S, Milev-Milovanovic I, Wilson M, Bengten E, Clem LW, Miller NW, et al. Identification and expression analysis of cDNAs encoding channel catfish type I interferons. Fish Shellfish Immunol. 2006 21:42-59.

38. Plant KP, Thune RL. Cloning and characterisation of a channel catfish (Ictalurus punctatus) Mx gene. Fish Shellfish Immunol. 2004 16:391-405.

39. Xing J, Lin T, Zhan W. Variations of enzyme activities in the haemocytes of scallop Chlamys farreri after infection with the acute virus necrobiotic virus (AVNV). Fish Shellfish Immunol. 2008 25:847-52.

40. Rosa RD, de Lorgeril J, Tailliez P, Bruno R, Piquemal D, Bachere E. A hemocyte gene expression signature correlated with predictive capacity of oysters to survive Vibrio infections. BMC Genomics. 2012 13:252-63.

41. Green TJ, Dixon TJ, Devic E, Adlard RD, Barnes AC. Differential gene expression of antioxidant enzymes in Sydney rock oysters, Saccostrea glomerata (Gould) selected for disease resistance. Fish Shellfish Immunol. 2009 26:799-810.

42. He X, Zhang Y, Yu Z. An Mpeg (macrophage expressed gene) from the Pacific oyster Crassostrea gigas: Molecular characterisation and gene expression. Fish Shellfish Immunol. 2011 30:870-6.

43. Fleury E, Huvet A. Microarray analysis highlights immune response of Pacific oysters as a determinant of resistance to summer mortality. Mar Biotechnol. 2012 14:203-17.

44. Zhang L, Li L, Zhang G. A Crassostrea gigas Toll-like receptor and comparative analysis of TLR pathway in invertebrates. Fish Shellfish Immunol. 2011 30:653-60. 
Table 1: Primer pairs used and amplification efficiency of each primer set in real-time RT qPCR expression analysis. The Genbank accession number or publication reference is provided for each gene.

\begin{tabular}{lcllcc}
\hline Gene & Genbank or Ref & Sense Primer & AntiSense Primer & $\mathbf{R}^{\mathbf{2}}$ & Efficiency \\
\hline EFU & AB122066 or Ref 29 & GAGCGTGAACGTGGTATCAC & ACAGCACAGTCAGCCTGTGA & 0,999 & 95,7 \\
TLR & Ref 12 & GCAGGACTCCACTTTCTCAC & GTTGGCACCCAGGTAAAGG & 0,999 & 101,4 \\
MyD88 & DQ530619 & AGGTACCGGCTGTGATACGA & TTCAAACGCCACCAAGACTG & 0,999 & 81,1 \\
IkB & DQ250326 & GAAAAAGTGGCAAGAGTGTC & GAAGAGTCATCGAAAGCAAC & 0,999 & 97,2 \\
Rel & AAK72690 & GCTGAACCAGAACCTCATGA & CGAAGGACATGTTCTGATCC & 0,995 & 104,2 \\
IRF-2 & EKC43155 & CGAAACGCAGAAACTGTTC & ATTTGCCTTCCATCTTTTGG & 0,996 & 93,7 \\
IFI44 & FJ440108 & AAGATCCAACGATGAAAGAC & TTGTCGACATCACTACAAAC & 0,993 & 117,3 \\
PKR & EKC34807 & GAGCATCAGCAAAGTGTTGAG & GTAGCACCAGGAGATGGTTC & 0,999 & 98,0 \\
OAS & EKC21335 & CACCCATAGCGTGGACATAC & GCAGTGGAGCGAGAGCTG & 0,999 & 97,4 \\
Mpeg1 & EF627979 & GCCACCGAAAGCCGGAGAAGATGTC & ACCGAGACCGAGTTTCAGGGGGTAG & 0,999 & 82,7 \\
C9/c10 & Ref 28 & GAGGGAAATTTGCGAGAGAA & ATCACCGGCAGACGTAGG & 0.995 & 95.0 \\
\hline
\end{tabular}

\section{Figures}

Figure 1: Conceptual diagram of the "interferon-like "pathway in molluscs [adapted from 24]. Homologues of toll-like receptor, NF-kB and interferon regulatory factors are conserved in molluscs $[15,28,29,44]$. Mammalian interferon activates a STATlike pathway in molluscs [14] and induces them into an antiviral state [13]. Classic interferon stimulated effector molecules, such as $\mathrm{Mx}$, are present in molluscs and their corresponding mRNA levels are upregulated in response to virus injection [19].

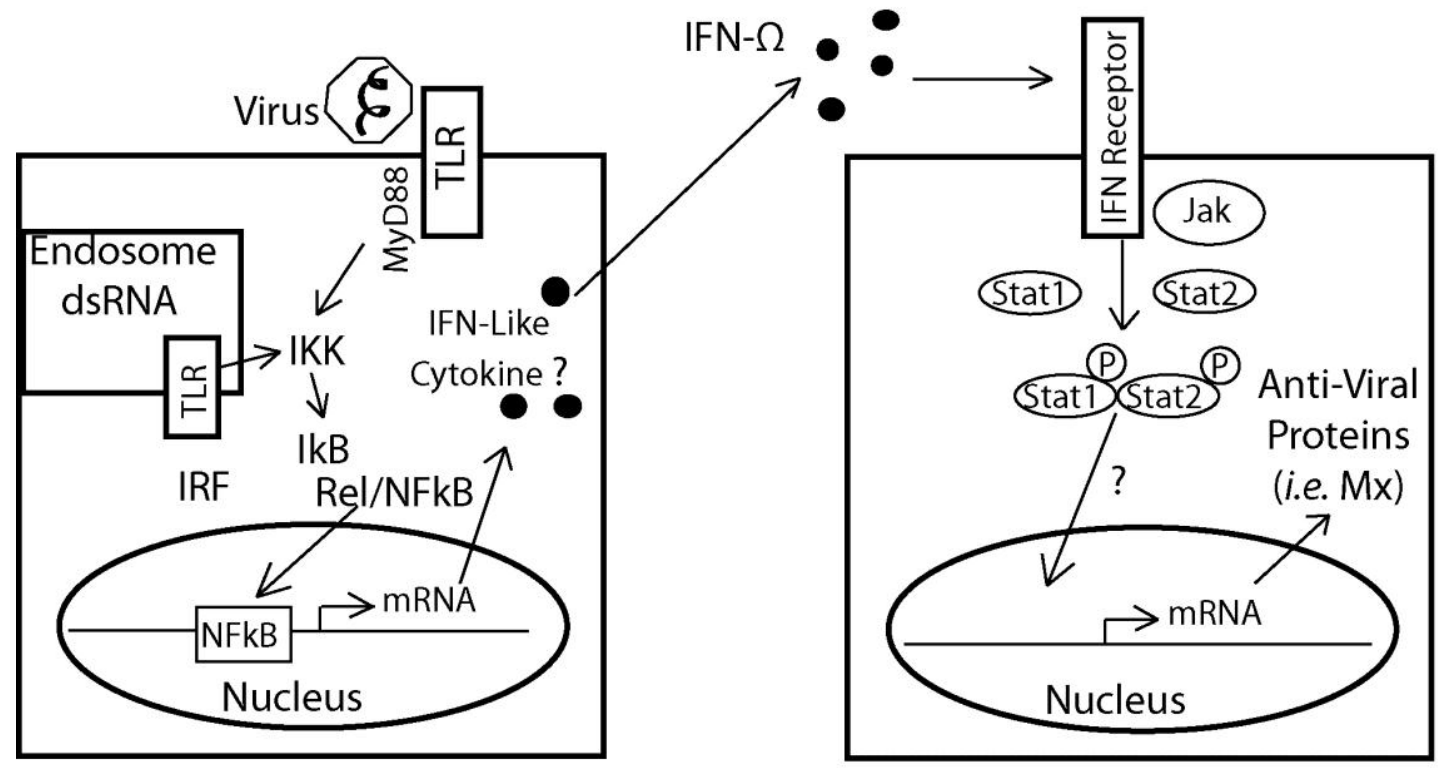

Virus-Infected Cell

Virus-Stimulated Cell 
Figure 2: OsHV-1 DNA detection by quantitative PCR in whole spat injected with either poly I:C or seawater and challenge with OsHV-1 $\mu$ var or control homogenate. Results of the first experiment (A) and second experiment (B) are expressed as the mean number of C9/C10 copies detected per 20 ng of genomic DNA extracted from whole oyster spat (mean $\pm \mathrm{SE}$ ). The proportion of oysters containing OsHV-1 DNA (34 cycles of qPCR) in each group is also presented.
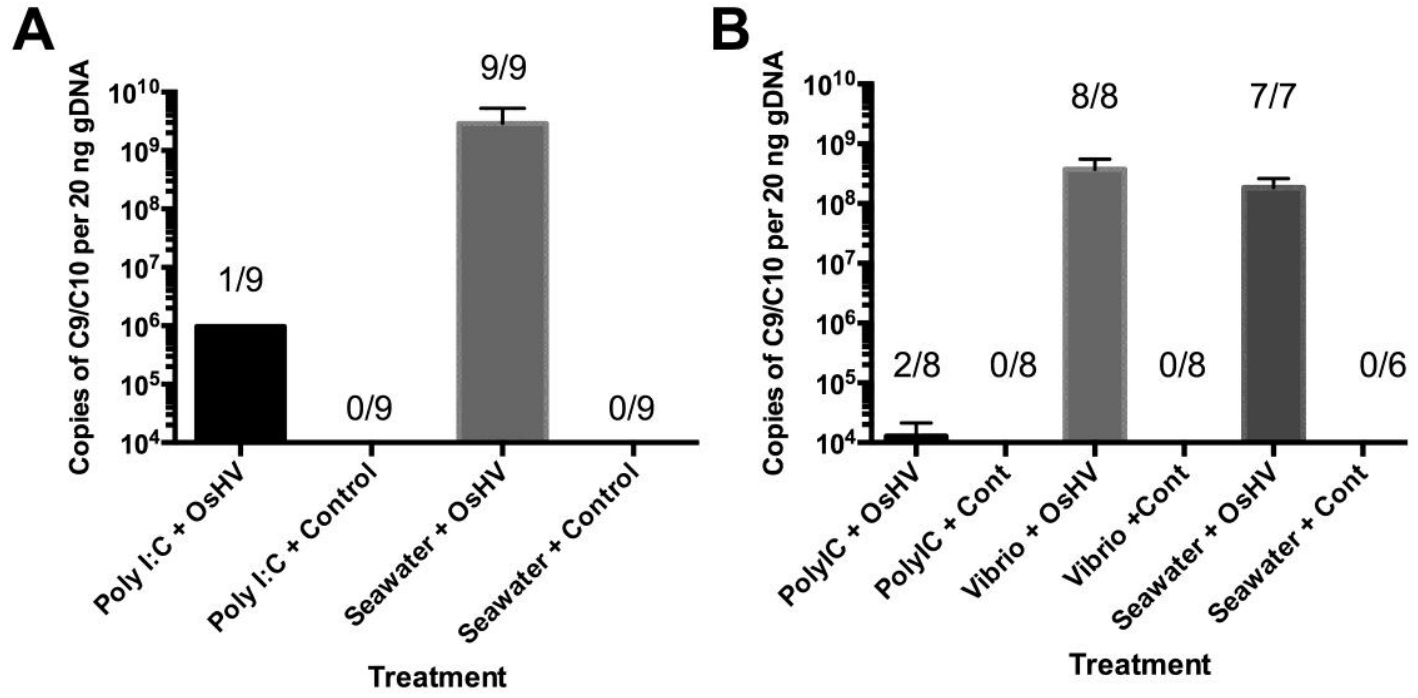

Figure 3: Gene expression of selected target genes in poly I:C protection study 1 and 2. The normalised expression of Cg-TLR (graph A and B), MyD88 (graph C and D), Cg-Rel (graph E), Cg-IRF (graph F), Cg-Mpeg (graph G and H), Cg-PKR (graph I and $\mathrm{J}$ ) and $\mathrm{Cg}$-IFI44 (graph $\mathrm{K}$ and $\mathrm{L}$ ) is presented. The expression level of $\mathrm{Cg}-\mathrm{Rel}$ and $\mathrm{Cg}$-IRF were only measure in protective study 2. Bar represent normalised expression following priming (24 hrs) and challenge (72 hrs) with either OsHV-1 $\mu$ var or control homogenates. Gene expression is presented relative to the EFU housekeeping gene $\left(2^{-\Delta \Lambda C t}\right.$, mean $\left.\pm S E\right)$. The affect of priming and OsHV-1 $\mu$ var infection on expression of target genes was determined using two-way analysis of variance (ANOVA). Different letters indicate significant differences between treatments $(p<$ 0.05 , Tukey's HSD). Horizontal brackets represent statistical differences due to priming $(p<0.05)$. 
Protective Study 1

A
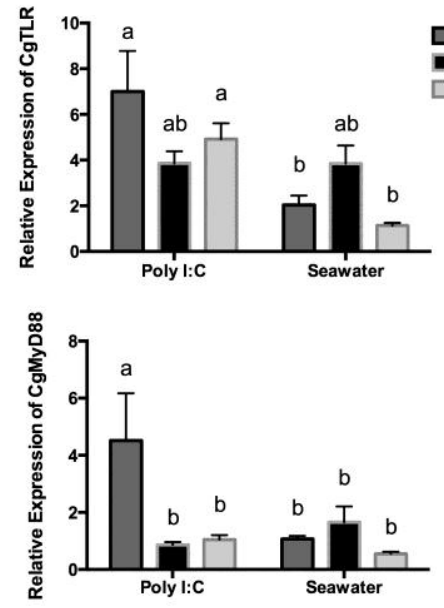

E

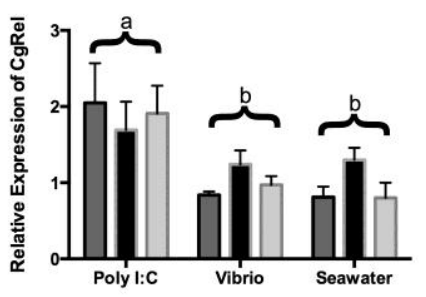

G

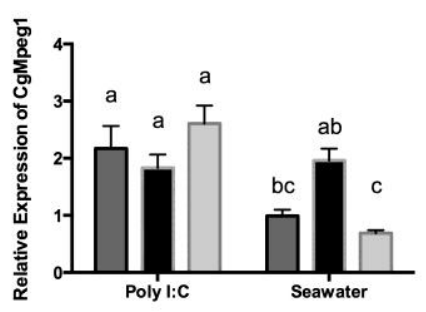

I

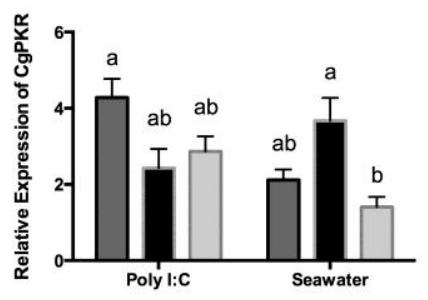

$\mathrm{K}$

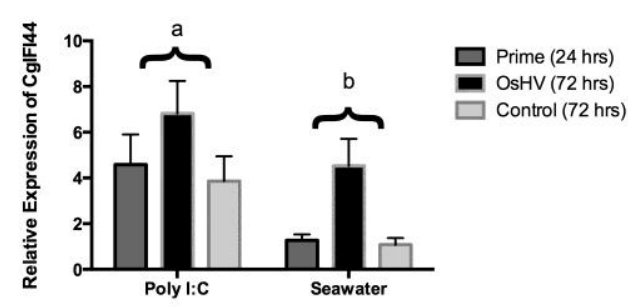

Protective Study 2

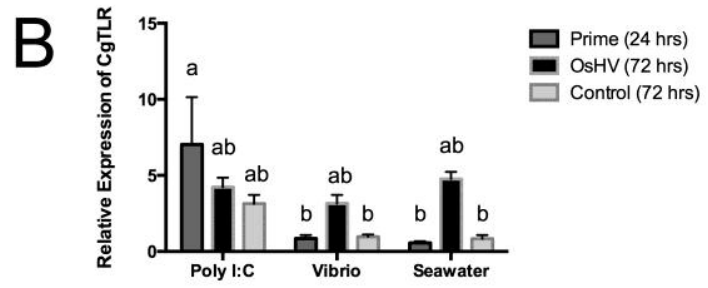

D

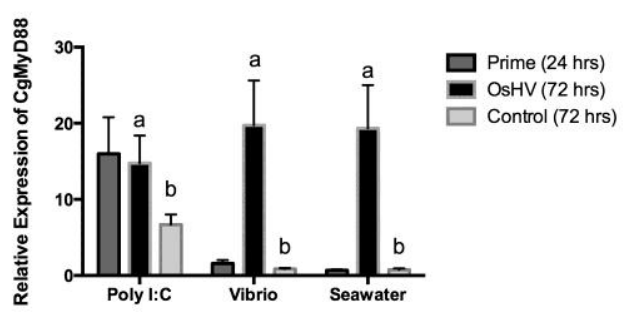

$F$

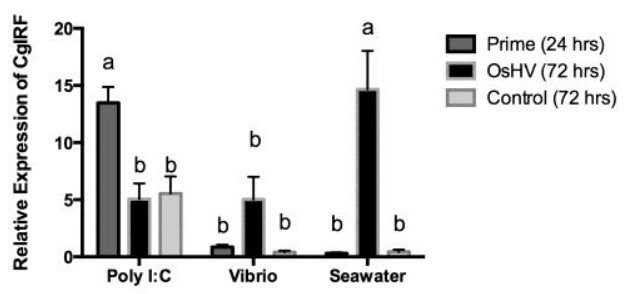

$\mathrm{H}$
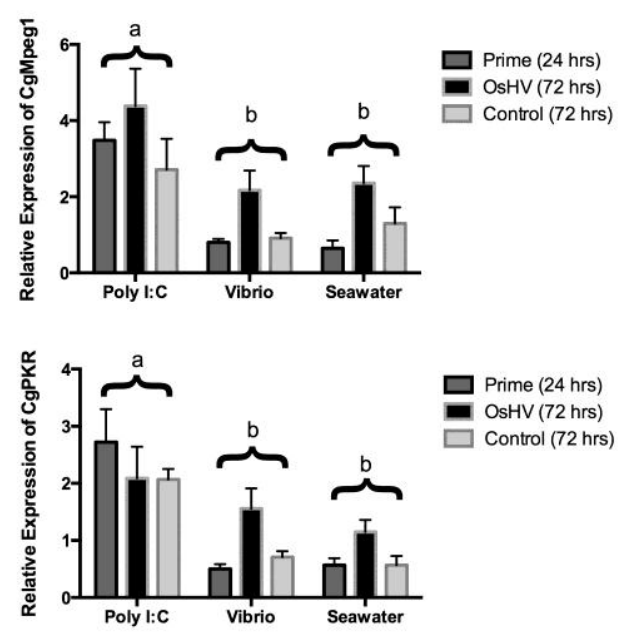

L

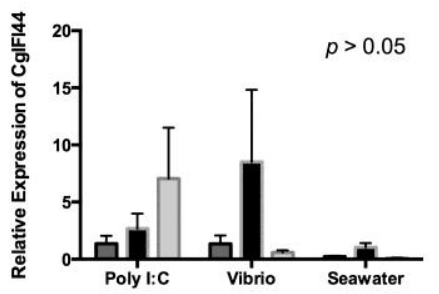

